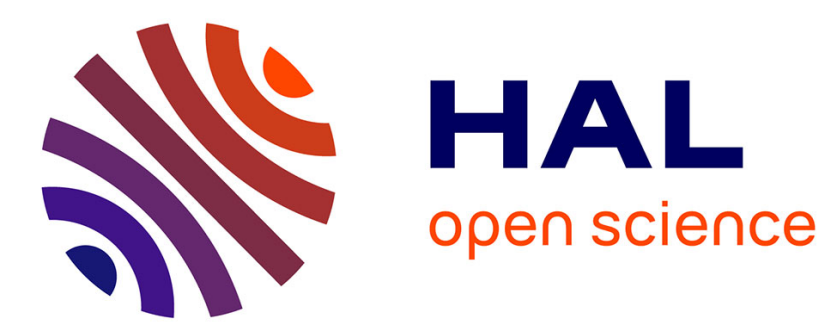

\title{
FIELD EVAPORATION CHARGE STATE OF BORON IONS : A TEMPERATURE EFFECT STUDY
}

\author{
A. Menand, C. Martin, J. Sarrau
}

\section{To cite this version:}

A. Menand, C. Martin, J. Sarrau. FIELD EVAPORATION CHARGE STATE OF BORON IONS : A TEMPERATURE EFFECT STUDY. Journal de Physique Colloques, 1984, 45 (C9), pp.C9-95-C9-98. 10.1051/jphyscol:1984917 . jpa-00224395

\section{HAL Id: jpa-00224395 https://hal.science/jpa-00224395}

Submitted on 1 Jan 1984

HAL is a multi-disciplinary open access archive for the deposit and dissemination of scientific research documents, whether they are published or not. The documents may come from teaching and research institutions in France or abroad, or from public or private research centers.
L'archive ouverte pluridisciplinaire HAL, est destinée au dépôt et à la diffusion de documents scientifiques de niveau recherche, publiés ou non, émanant des établissements d'enseignement et de recherche français ou étrangers, des laboratoires publics ou privés. 


\title{
FIELD EVAPORATION CHARGE STATE OF BORON IONS :
}

\section{A TEMPERATURE EFFECT STIUDY}

\author{
A. Menand, C. Martin and J.M. Sarrau
}

Laboratoire de Microscopie Ionique ${ }^{+}$, Faculté des Sciences de Rouen, BP 67, 76130 Mont-Saint-Aignan, France

Résumé - Une étude de la charge des ions Bore évaporés par effet de champ,

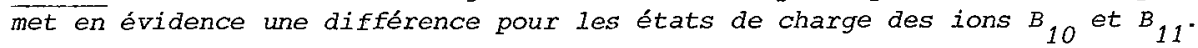
Cette différence dépend de la température de l'échantillon. Une explication de cet effet dû au départ des ions à basse température par effet tunnel ionique est donnée.

Abstract - We have observed the mass to charge ratio of field evaporated Boron ions. A difference between the charge state of $B_{10}$ and $B_{11}$ ions is observed. This difference is temperature dependent. An explanation is given in terms of ionic tunneling desorption of Boron ions at low temperature.

\section{INTRODUCTION}

As it has been previously reported $|1|$, an isotopic variation in field evaporation charge state of boron ions has been observed. The proportion of ${ }_{10}{ }_{10}$ ions field evaporating as doubly chaxged ions is found to be less than the corresponding figure for $B_{11}$ ions. This effect is predicted by the post-ionisation model of Haydock and Kingham $|2| \cdot B_{10}^{+}$ions being less massive than $B_{11}^{+}$ions travel faster and so spend less time in the "post-ionisation zone" in which the transition from $B^{+}$to $B^{2+}$ is expected to occur. The maximum of difference between the probabilities of post-ionisation calculated for Boron ions is $\Delta P=1.6 \%|1|$. In practice the observed difference $\Delta P_{\text {exp }}$ is much more pronounced than expected with $\Delta P$ exp $=4.6 \%$ for experiment at $78 \mathrm{~K}$.

It has been assumed by Menand and Kingham $|1|$ that this discrepancy could be explained in terms of evaporation of boron ions by ionic tunneling at low temperature. The purpose of this paper is to test this assumption by varying the sample temperature.

\section{EXPERIMENTAL}

The experiments were made with samples of $\mathrm{Fe} \mathrm{Ni}$ Mo $B$ metallic glass, the specimens were prepared from tapes of $50 \mathrm{~km}$ thickness and about $0.2 \mathrm{~mm}$ width, by anodic electropolishing in a solution of $10 \%$ perchloric acid in 2-Butoxyethanol. We used a ToF atom probe |3| with a $30 \mathrm{~cm}$ flight length which allows a large analysis area. Timing was by means of a three channel $400 \mathrm{MHz}$ digital counter with a dead time of $5 \mathrm{~ns}$, low temperatures was obtained by means of a cryogenerator.

\section{RESULTS AND DISCUSSION}

\section{1 - Temperature dependence of isotopic_effect}

Table 1 gives the results obtained at temperature values ranging from $170 \mathrm{~K}$ to $300 \mathrm{~K}: 20304$ boron ions were detected of which $19.88 \%$ were ${ }_{10}{ }_{10}$ in good agreeUA CNRS 808 
ment with the isotopic relative abundance. The average proportion of $B_{10}$ in the doubly charged peak is $19.46 \%$ whereas the proportion of $B_{10}$ in the singly charged peak is $20.41 \%$. The average difference $\Delta_{P}$ exp between the probabilities of postionisation of $B_{10}$ and $B_{11}$ is $1.5 \%$.

\begin{tabular}{|c|r|r|r|r|r|r|r|}
\hline Experiment & $B_{10}^{2+}$ & $B_{11}^{2+}$ & $B_{10}^{+}$ & $B_{11}^{+}$ & $B_{10^{2+} \Sigma B_{10} \%}$ & $B_{11^{2+} / \Sigma B_{11} \%}^{\Delta P_{\exp } \%}$ \\
\hline 1 & 235 & 996 & 360 & 1342 & 39.5 & 41.8 & +2.3 \\
2 & 382 & 1472 & 320 & 1126 & 54.4 & 56.6 & +2.2 \\
3 & 224 & 933 & 181 & 692 & 55.3 & 57.4 & +2.1 \\
4 & 152 & 663 & 124 & 475 & 55.1 & 58.2 & +3.1 \\
5 & 425 & 1658 & 301 & 1177 & 58.5 & 58.5 & 0 \\
6 & 393 & 1789 & 270 & 1209 & 59.3 & 59.7 & +0.4 \\
7 & 413 & 1723 & 256 & 1043 & 61.7 & 62.3 & +0.6 \\
Total & 2224 & 9204 & 1812 & 7064 & 55.1 & 56.58 & 1,48 \\
\hline
\end{tabular}

Table 1 - Number of $B_{10^{\prime}}^{2+} B_{10^{\prime}}^{+} B_{11}^{2+}$ and $B_{11}^{+}$ions observed in seven experiments of $\mathrm{Fe} N \mathrm{~N}$ Mo $\mathrm{B}$, at temperature ranging from $170 \mathrm{~K}$ to $300 \mathrm{~K}$. Each experiment gives an estimate of the relative abundance of $B_{10}^{2+}$ and $B_{11}^{2+}$ ( $i . e\left(B_{10^{2}}^{2+\Sigma B} 10^{2}\right.$ ) and $\left.\left(B_{11}^{2+} / \Sigma B_{11}\right)\right)$ and of the difference in these quantities, $\Delta P_{\exp }$

The results on the abundance of singly and doubly charged ions of the two isotopes of boron at temperature between $20 \mathrm{~K}$ and $300 \mathrm{~K}$ are summarised in table 2 , they show a significant temperature effect.

\begin{tabular}{|c|r|r|r|r|r|r|c|}
\hline Temperature & \multicolumn{1}{|c|}{$\begin{array}{c}B_{10}^{2+} \\
B_{10}^{+}\end{array}$} & $B_{11}^{2+}$ & $B_{11}^{+}$ & $B_{10^{2+} / \Sigma B_{10} \%}$ & $B_{11}^{2+} / \Sigma B_{11} \%$ & $\Delta P_{\exp }$ \\
\hline $20 K$ & 414 & 627 & 1921 & 2028 & 39.8 & 48.6 & +8.8 \\
$78 K$ & 102 & 108 & 448 & 404 & 48.6 & 52.6 & +4 \\
$170-240 K$ & 993 & 985 & 4034 & 3635 & 50.2 & 52.6 & +2.4 \\
$300 K$ & 1231 & 827 & 5170 & 3429 & 59.8 & 60.1 & +0.3 \\
\hline
\end{tabular}

Table 2 - Number of $B_{10^{\prime}}^{2+}, B_{10^{\prime}}^{+} B_{11}^{2+}$ and $B_{11}^{+}$ions observed in the experiments on Fe Ni MB for different temperatures lying from $20 \mathrm{~K}$ to $300 \mathrm{~K}$

In the temperature range $170-300 \mathrm{~K}$ the difference $\Delta P_{\text {exp }}$ is small $0.3-2.4 \%$ which is consistent with the predicted value of $1.6 \%$, but at lower temperature $\Delta P$ exp is larger, up to $8.8 \%$ at $20 \mathrm{~K}$. These results support our assumption of ionic tunneling at low temperature. The occurence of ionic tunneling means that the lighter $B_{10}$ ions will be more easily field evaporated than $B_{11}$, so they may be evaporated at field strength slightly lower than $B_{11}$. That is, if $B^{11}$ ions are only evaporated at the maximum of the electric field pulse, ${ }_{10}$ ions may be evaporated when the field is just less than its maximal value. As post-ionisation probabilities are strongly dependent on field strength $|1|$, only a $0.5 \%$ difference in evaporation field strength is required to give à $3 \%$ difference in post-ionisation probabilities. 


\section{2 - Constant field stength study}

We have prepared a specimen with a very narrow taper angle which meant that the desorption field remained constant (with the tip voltage held constant) during the desorption of many atoms. The steadiness of the tip radius was verified by the measurement of BIV before and after each experiment. With this specimen we have performed experiments with increasing temperature (by switching off the cryogenic refrigerator). So during the course of the experiment, and as the evaporated ions were detected, the tip temperature was slowly increasing. Figure 1 gives the cumuative number of $B^{2+}$ ions versus the total number of Boron detected ions, the corresponding temperatures are also indicated.

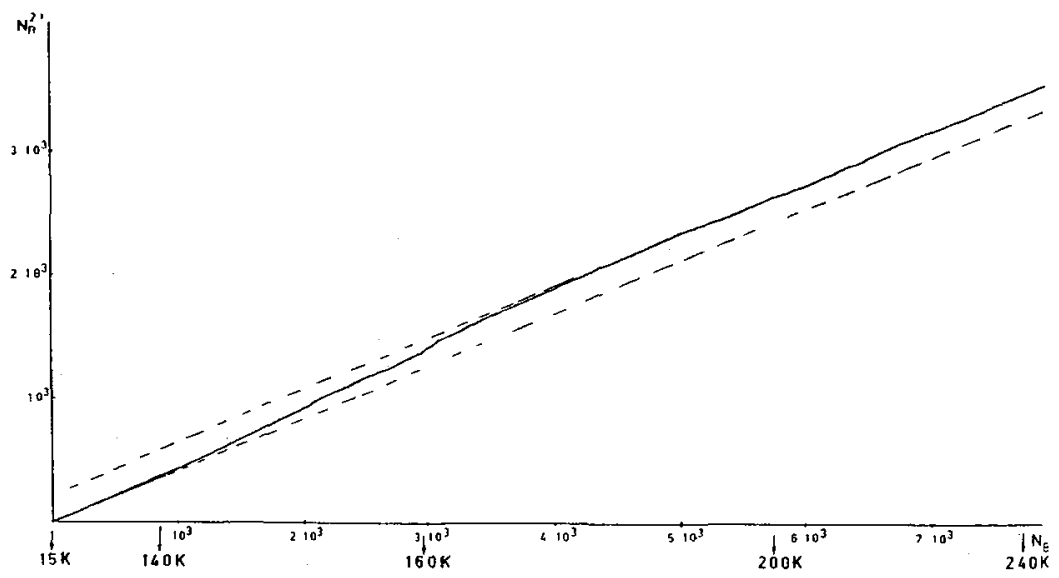

Fig. 1 - Cumulative number of $B^{2+}$ ions observed against the total number of $B$ ions observed

The sharp slope change within $140 \mathrm{~K}$ is the result of an interesting artefact. For temperatures under $140 \mathrm{~K}$ the evaporation rate was increasing very slowly and the average number of detected ions per pulse $\bar{n}$ lying from $5.10^{-3}$ to $4.10^{-2}$, but near $140 \mathrm{~K}$ the evaporation rate increased suddenly $\bar{n}>3$, three Boron ions or more were produced for each pulse but obviously only 3 ions could be stored in the three channels digital counter. In this saturated regime doubly charged ions appear more abundant because they reach the detector first.

This sudden increase in the evaporation rate is interpreted as a change in the evaporation process from an essentially tunneling desorption of boron ions, to an essentially thermally activated evaporation. The transition temperature $T_{0}$ will be $140 \pm 5 \mathrm{~K}$.

It is particularly interesting to notice the steadiness of the charge ratio ${ }_{B}^{2+} / \Sigma B$ at low and at high temperature (excepted in the saturated zone $140-165 \mathrm{~K}$ ). This is an evidence for the post-ionisation model of Kingham, the charge state of boron ions is a function of field and not of temperature

\section{Acknowledgements}

The authors wish to thank $D r D . R$. Kingham for fruitful discussions and valuable comments. 


\section{REEERENCES}

11 A. MENAND and D. R. KINGHAM

J. Phys. D : Appl. Phys., 17 (1984) 203

$|2| R$. HAYDOCK and D. R. KINGHAM

Phys. Rev. Lett., 44 (1980) 1520

|3| C. MARTIN, D. BLAVETTE and J. M. SARRAU Rev. Phys. Appl., 19 (1984) 27 